\title{
MAPPING QUANTITATIVE TRAIT LOCI (QTL) CONTROLLING SEED MORPHOLOGY AND DISK DIAMETER IN SUNFLOWER (Helianthus annuus L.)
}

\author{
Yue, B. ${ }^{1,2}$, Cai, X. ${ }^{1}$, Yuan' W. ${ }^{3}$, Vick, B. ${ }^{4}$, and Hu, J. ${ }^{5^{*}}$ \\ ${ }^{1}$ Department of Plant Sciences, North Dakota State University, Fargo, \\ ND 58105, USA \\ ${ }^{2}$ National Key Lab of Crop Genetic Improvement, Huazhong Agricultural \\ University, Wuhan 430070, China \\ ${ }^{3}$ Langfang Academy of Agricultural and Forest Sciences, \\ Langfang 065000, China \\ ${ }^{4}$ U. S. Department of Agriculture, Agricultural Research Service, Northern Crop \\ Science Laboratory, Fargo, ND 58105, USA \\ ${ }^{5}$ U. S. Department of Agriculture, Agricultural Research Service, \\ Western Regional Plant Introduction Station, Pullman, WA 99164, USA
}

Received: February 07, 2009 Accepted: June 10, 2009

\begin{abstract}
SUMMARY
Seed morphology and disk diameter are agronomically most important traits for the confection sunflower. This paper reports the results of an analysis of quantitative trait loci (QTLs) underlying 10 seed morphological traits including seed and kernel size, shape and stripe, and disk diameter in both $\mathrm{F}_{2}$ population and $\mathrm{F}_{2: 3}$ families derived from an oilseed by confection cross. A linkage map containing 165 target region amplification polymorphism (TRAP) and 44 simple sequence repeat (SSR) markers was constructed from $120 \mathrm{~F}_{2}$ plants. This map contained 17 linkage groups and spanned a total genetic distance of $1784.3 \mathrm{cM}$. A total of 51 QTLs were detected and 32 of them were identified in both generations. Each QTL explained 5.1-29.3\% of the phenotypic variation, suggesting these traits were controlled by multiple genes. Most of the QTLs were clustered in six chromosomal regions. Two of the three QTLs identified for disk diameter were also located in two of the six regions. Moreover, alleles from the confection line at these QTLs had positive effects on these traits. Both QTL congruence and correlation analysis revealed that different genetic bases are responsible for seed shape, stripe, and other confection traits. The information generated by this study will facilitate confection sunflower breeding.
\end{abstract}

Key words: sunflower, quantitative trait loci, mapping, seed size, kernel size, shape, disk diameter

* Corresponding author: Phone: (509) 335-3683; Fax: (509) 335-6654;

e-mail: jinguo.hu@ars.usda.gov 


\section{INTRODUCTION}

The cultivated sunflower (Helianthus annuus L.) is one of the staple oilseed crops of the world. There are two types of cultivated sunflowers, oilseed type and confection type. Although the oilseed is the major type of sunflower cultivated, the market and production area of confection sunflower has increased in recent years. The seeds of confection hybrids are typically gray or white in color with black or brown stripes, large-sized, and have a low kernel-to-pericarp weight ratio. In contrast, the seeds of oilseed cultivars are usually solid black, small-sized, and have a high kernel-to-pericarp weight ratio. It has been reported that the hull color is controlled by pigments in three layers:

1. the epidermis is either unpigmented, solid brown or black, or black- or brown-striped,

2. the hypodermis is either anthocyanin pigmented (black) or unpigmented, and

3. the phytomelanin layer is either present (black) or absent (Miller and Fick, 1997).

Through phenotypic analyses of mutations several hull pigment loci have been detected (reviewed by Miller and Fick, 1997). Hyp, a hypodermis pigment locus, has been genetically mapped (Leon et al., 1996). Recently, Tang et al. (2006) mapped genes governing phytomelanin pigment $(P)$ and hypodermal pigment (Hyp) on linkage groups 16 and 17, respectively. However, other seed traits including seed size and seed shape are typically quantitative traits which are controlled by multiple genes, and only limited work has been conducted on the genetic basis of these traits in sunflower.

The advent and development of molecular markers and genetic maps has provided the necessary tools to gain understanding of the genetic basis of the economically important traits and facilitate plant breeding via marker-assisted selection. To date, several linkage maps have been constructed using different molecular markers, including RFLP, RAPD, and SSR in sunflower (Berry et al., 1995; Gedil et al., 2001; Tang et al., 2002). Recently, Lai et al. (2005) mapped 243 markers derived from sunflower expressed sequence tags (ESTs) to the 17 previously established linkage groups. The target region amplification polymorphism (TRAP) marker technique (Hu and Vick, 2003) takes advantage of the annotated EST information to generate PCR-based markers near the target sequences. TRAP has been successfully used in defining the linkage group ends $(\mathrm{Hu}, 2006)$ and in mapping a nuclear male-sterile $\left(\mathrm{ms}_{\mathrm{g}}\right.$ ) gene (Chen et al., 2006) and an apical branching $(b)$ gene (RojasBarros et al., 2005) in sunflower.

Quantitative trait loci (QTLs) can be identified by advanced computer software in chromosomal regions on the molecular marker linkage maps. Although confection sunflower accounts for 15 to $20 \%$ of the total US sunflower production, research activities have usually been focused on oilseed sunflower (Mestries et al., 
1998; Mokrani et al., 2002; Bert et al., 2004; Rönicke et al., 2005; Micic et al., 2004). Burke et al. (2002) first identified 14 QTLs for seed weight, seed length, and seed width. Tang et al. (2006) detected 34 QTLs for seven seed traits, and they also found that some QTLs with large effects on the seed traits are tightly linked to the branching and pericarp pigment loci. Recently, Wills and Burke (2007) and Baack et al. (2008) also identified some QTLs for seed traits and disk diameter using populations derived from crop-wild hybrids.

In this study, we analyzed the QTLs underlying 10 seed morphological traits and disk diameter in an $\mathrm{F}_{2}$ population derived from a cross between an oilseed line, HA89, and a confection sunflower line to elucidate the genetic basis of these traits.

\section{MATERIALS AND METHODS}

\section{Parental Lines and the Segregating Population}

Two sunflower inbred lines with significant differences in some seed morphological traits were selected to develop the $\mathrm{F}_{2}$ population used in the current study. The female was a USDA-ARS released, public oilseed sunflower inbred maintainer line, HA89 (PI 599773), and the male was a confection sunflower line (designated as LSS for its long seed size) introduced from China. The $F_{1}$ plants were grown in the greenhouse to produce $\mathrm{F}_{2}$ seeds. One hundred and twenty $\mathrm{F}_{2}$ plants were planted in one-gallon plastic pots in the greenhouse in the winter of 2006, with one plant per pot. Ninety-two $\mathrm{F}_{2: 3}$ families ( 28 plants did not produce enough seeds due to severe self incompatibility) and their parents were planted in the experimental field in Fargo, ND, USA, during the growing season of 2007 using a randomized complete block design with two replicates, with 15 to 20 plants grown in single-row plots.

\section{Traits and Measurements}

To map the self-incompatibility $(S)$ gene in this population, seed set rate of each $\mathrm{F}_{2}$ plant was investigated. Plants with two kinds of seed set rate, those with normal heads and those with sterile heads (fewer than 10 filled seeds), were observed and recorded before harvesting.

Disk diameter (DD, $\mathrm{cm}$ ) was measured before harvesting on fully opened heads of individual $\mathrm{F}_{2}$ plants and on each plant in every $\mathrm{F}_{2: 3}$ family row except for the two plants at both ends of the row. Ten seeds from each $\mathrm{F}_{2}$ plant and one representative seed from each plant from each $\mathrm{F}_{2: 3}$ family row, except for the two plants at both ends of the row, were sampled to measure the seed traits after drying at $32^{\circ} \mathrm{C}$ for a week. Sampling and measuring of seed traits were repeated two times in the $\mathrm{F}_{3}$ generation.

The images of the seeds from each line or family were taken using a digital camera at a fixed distance for all samples (Figure 1). The parameters of seed length (SL), and seed width (SW) were generated from the image pixels with the public 
software TomatoAnalyzer, version 1.2 (Brewer et al., 2006). The pixel values were then converted to centimeters by calibrating the actual length per seed $(\mathrm{cm})$ measured on ten seeds from ten random plants. The same procedures were followed to obtain the measurement on kernel length ( $\mathrm{KL}, \mathrm{cm} / \mathrm{kernel}$ ), and kernel width (KW, $\mathrm{cm} /$ kernel) from the kernels manually dehulled from the seeds.
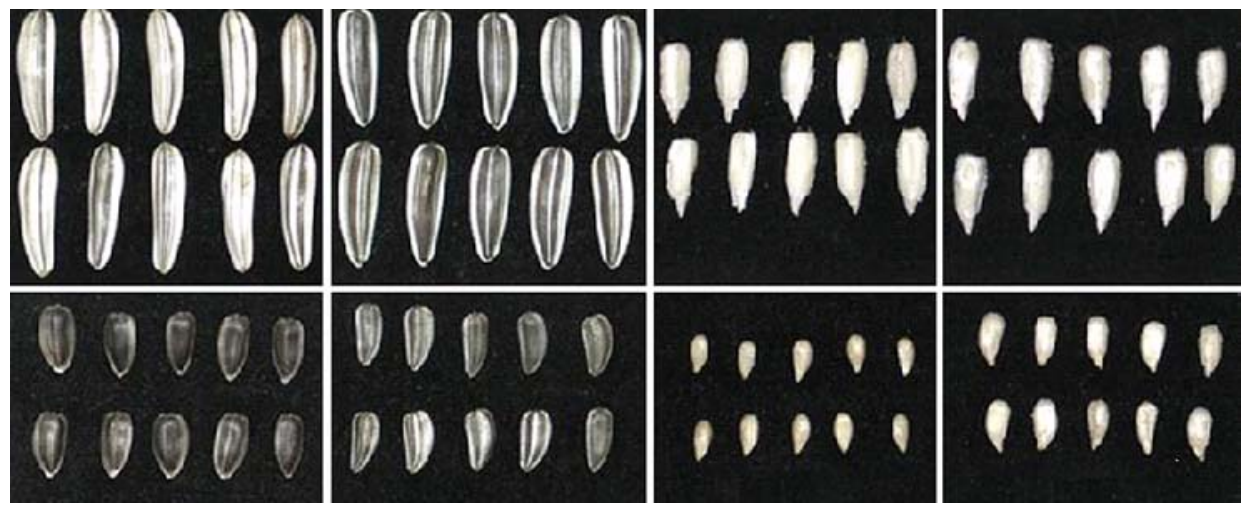

Figure 1: Sample digital images used to measure seed and kernel parameters.

The seeds and kernel from each plant were weighed, and 100-seed weight (SWT, g) and 100-kernel weight (KWT, g) were calculated. The ratios of seed length to width (SLW, \%), kernel length to width (KLW, \%), and kernel-to-seed weight ratio (KSR, \%) were also calculated. Stripe (STR) on the hull was visibly scored from 0 (totally dark) to 3 (white with the least stripes).

\section{DNA Preparation and Marker Generation}

Total genomic DNA was isolated from about $50 \mathrm{mg}$ (fresh weight) of leaf tissue sampled from individual plants of the parental lines and the $\mathrm{F}_{2}$ population using the Qiagen DNeasy ${ }^{\circledR} 96$ Plant Kit (Qiagen, Valencia, CA), following the manufacturer's instructions. DNA concentrations were adjusted to approximately $10 \mathrm{ng} / \mu \mathrm{l}$ for PCR amplification. To generate TRAP markers for map construction, 20 available fixed primers designed for related projects in our laboratory were used in the current study. These fixed primers were designed against the sequences of annotated ESTs related to chlorophyll synthesis, gibberellin synthesis, and the conserved plant telomere repeats. These sequences were obtained from the Compositae Genome Project Database (http://cgpdb.ucdavis.edu) and National Center for Biotechnology Information (http://www. ncbi.nlm.nih.gov) websites. Nine arbitrary primers labeled with either IR (infrared) 700 or IR 800 dyes were used. Table 1 lists the detailed information of all the primers. The TRAP assays followed the updated procedures described by $\mathrm{Hu}$ (2006). The TRAP markers were designated by the combination of the code of the fixed primer, the code of the arbitrary primer, and the fragment size in base pairs.

To align the linkage groups constructed in this study with the published SSR map, a total of 150 mapped SSR primer pairs from the 17 linkage groups (Yu et al., 
2003) were selected in the initial screening for polymorphisms between the two parents, and the polymorphic SSRs were used to genotype the whole $\mathrm{F}_{2}$ population. SSR assays were carried out by following the procedures described by Tang et al. (2002).

Table 1: Information on fixed and arbitrary primers used in the current study

\begin{tabular}{|c|c|c|}
\hline Code & Sequence ID & Sequences 5'-3' \\
\hline \multicolumn{3}{|c|}{ Fixed primer } \\
\hline T98 & QHA14E20 & СTC CTA AAA GGT AAC CTG CT \\
\hline T99 & QHB26P17 & GTT TTC CGT CAT ACT CGT TA \\
\hline T100 & QHB33|23 & GAA GGG GTC AAA AAT TTA AC \\
\hline T101 & QHB34F17 & TCC ACA CTT TTG AAG TCA TT \\
\hline T103 & QHK1O04 & GAT ACA GGT TAT GGC AGA AA \\
\hline T104 & QHK7L05 & TTA TGT CTA TGG CAC CAA CA \\
\hline T105 & QHL12I06 & GCT TAC CGT CAT CAA GAA AC \\
\hline T106 & QHL15C24 & GAA TGT CAC TTG ATT TTG CT \\
\hline T107 & QHL9B24 & CAA TAT ССТ TCC AAA ССТ GA \\
\hline T108 & DY475501 & CTC TTT GTA TGT GTT GTC CG \\
\hline $\mathrm{T} 110$ & CV987281 & CAT ACA AGG TGG TCG AAA TT \\
\hline T111 & EC683354 & AGG AAA TGT CTA TTT GGC AA \\
\hline T112 & QHJ12G10 & ACC ACA CAA TCA TGA CTA GG \\
\hline T114 & QHJ4A19 & TAA TAG CAA AAG CTC CAA TG \\
\hline T116 & QHB29B22 & GCA TTA TAC TTT GGT GGA GA \\
\hline T117 & QHM10I05 & ATT TGT TTG TTT GTT TTT GG \\
\hline T64 & TeloR $^{\mathrm{a}}$ & AAC CCT AAA CCC TAA ACC \\
\hline T66 & TeloRT ${ }^{\mathrm{a}}$ & CCC TAA ACC CTA AAC СCT AAA T \\
\hline T68 & TeloTRG $^{\mathrm{a}}$ & CCC AAA ACC CAA AAC CCA AAA G \\
\hline T123 & MAX3BR $^{b}$ & ACG TTA TGA GCC CCA TGA AGA \\
\hline \multicolumn{3}{|c|}{ Arbitrary primer } \\
\hline R03 & TRAP03(IR-700) & CGTAGCGCGTCAATTATG \\
\hline R13 & TRAP013(IR-800) & GCGCGATGATAAATTATC \\
\hline R14 & TRAP014(IR-800) & GTCGTACGTAGAATTCCT \\
\hline R17 & ODD15(IR-700) & GCGAGGATGCTACTGGTT \\
\hline R18 & ODD26(IR-700) & CTATCTCTCGGGACCAAAC \\
\hline R19 & SA12(IR-700) & TTCTAGGTAATCCAACAACA \\
\hline R20 & SA14(IR-700) & TTACCTTGGTCATACAACATT \\
\hline $\mathrm{R} 21$ & SA4(IR-700) & TTCTTCTTCCCTGGACACAAA \\
\hline R22 & GA3(IR-800) & TСАТСТСАААССАТСТАСАС \\
\hline R23 & GA5(IR-800) & GGAACCAAACACATGAAGA \\
\hline
\end{tabular}

a: from Hu (2006) and ${ }^{b}$ from Rojas-Barros et al. (2005)

\section{Map Construction and QTL Analysis}

The linkage map was constructed using the computer program Mapmaker/EXP 3.0 (Lander et al., 1987) (LOD>4.5). Due to the dominant nature of the TRAP 
markers in this $\mathrm{F}_{2}$ population, only interval QTL mapping was performed with both $\mathrm{F}_{2}$ and $\mathrm{F}_{3}$ data employing the software program Mapmaker/QTL1.1 (Lander and Botstein, 1989; Lincoln et al., 1993). A LOD score of 2.4 was set for the threshold of the QTLs.

\section{RESULTS}

\section{Phenotype Analysis}

The phenotypic differences between the parents as well as the variation in the populations are summarized in Table 2 . LSS had significantly higher values than HA89 for most of the seed traits including SL, KL, SLW, KLW, SWT, KWT, and STR, whereas HA89 was significantly higher than LSS for the trait of KSR in both generations (Table 2).

Table 2: The performance of seed morphological traits in the $\mathrm{F}_{2}$ and $\mathrm{F}_{3}$ populations

\begin{tabular}{lcccccc}
\hline \multirow{2}{*}{ Traits $^{2}$} & \multirow{2}{*}{ HA89 } & \multirow{2}{*}{ LSS } & \multicolumn{5}{c}{$\mathrm{F}_{2} / \mathrm{F}_{2: 3}$ population } \\
\cline { 4 - 7 } & & & Mean & Range & Skewness & Kurtosis \\
\hline $\mathrm{SL}$ & $1.1 / 1.1^{\mathrm{b}}$ & $3.1^{*} / 2.2^{*}$ & $1.6 / 1.7$ & $(0.9-2.2) /(1.2-2.5)$ & $0.2 / 0.7$ & $0.1 / 1.3$ \\
$\mathrm{SW}$ & $0.6 / 0.5$ & $0.7 / 0.6$ & $0.6 / 0.6$ & $(0.3-0.8) /(0.5-0.9)$ & $-0.2 / 1.1$ & $0.3 /-2.1$ \\
$\mathrm{KL}$ & $-/ 0.8$ & $-/ 1.4^{*}$ & $1.2 / 1.2$ & $(0.7-1.4) /(0.9-1.5)$ & $-0.5 / 0.1$ & $1.1 / 0.4$ \\
$\mathrm{KW}$ & $-/ 0.5$ & $-/ 0.4$ & $0.5 / 0.5$ & $(0.3-0.6) /(0.4-0.6)$ & $-0.2 / 0.6$ & $0.1 / 1.4$ \\
$\mathrm{SLW}$ & $2.0 / 2.0$ & $4.6^{*} / 3.8^{*}$ & $2.8 / 2.8$ & $(2.0-4.1) /(2.2-4.5)$ & $0.8 / 1.4$ & $0.8 / 2.5$ \\
$\mathrm{KLW}$ & $-/ 1.9$ & $-/ 3.5^{\star *}$ & $2.6 / 2.7$ & $(2.1-3.2) /(2.1-3.5)$ & $0.2 / 0.3$ & $-0.2 / 0.9$ \\
$\mathrm{SWT}$ & $-/ 6.1$ & $-/ 12.3^{*}$ & $8.7 / 10.7$ & $(2.9-14.8) /(5.7-21.3)$ & $0.3 / 0.9$ & $-0.5 / 2.1$ \\
$\mathrm{KWT}$ & $-/ 4.6$ & $-/ 6.4^{*}$ & $6.2 / 6.6$ & $(2.4-10.0) /(4.0-11.2)$ & $0.1 / 0.9$ & $-0.6 / 1.6$ \\
$\mathrm{KSR}$ & $-/ 75.9^{\star *}$ & $-/ 51.7$ & $72.8 / 62.1$ & $(56.2-87.3) /(48.4-77.0)$ & $0.0 / 0.2$ & $-0.4 /-0.1$ \\
$\mathrm{STR}$ & $0.0 / 0.0$ & $3.0^{* *} / 3.0^{* *}$ & $1.7 / 1.5$ & $(0-3) /(0-3)$ & $-0.1 / 0.1$ & $-1.0 / 0.2$ \\
$\mathrm{DD}$ & $-/ 16.3$ & $-/ 16.7$ & $12.1 / 15.8$ & $(6.5-19.0) /(13.1-26.0)$ & $-0.2 / 1.3$ & $-0.0 / 3.8$ \\
\hline $\mathrm{a}$ & & &
\end{tabular}

a $\mathrm{SL}=$ seed length, $\mathrm{SW}=$ seed width, $\mathrm{KL}=$ kernel length, $\mathrm{KW}=$ kernel width, $\mathrm{SLW}=$ seed length to width ratio, $K L W=$ kernel length to width ratio, $S W T=100$-seed weight, $K W T=100$-kernel weight, $K S R=$ kernel-to-seed weight ratio, STR=stripe in hull, $D D=$ disk diameter.

b The values on the left side of the sign "/" are the data collected in the $F_{2}$ generation, and those on the right side were collected in $\mathrm{F}_{3}$ generation. ${ }^{*}$, ${ }^{*}$, significant higher than the other parent at the 0.05 and 0.01 probability levels.

The difference between the two parents was not significant for SW, KW, and DD. The means for SWT, KWT, and DD in the $\mathrm{F}_{3}$ generation were much higher than those for the $\mathrm{F}_{2}$ generation, and it was opposite for KSR. This could be explained by the different growing environments for the two generations because the $\mathrm{F}_{2}$ generation was grown in the greenhouse and the $\mathrm{F}_{3}$ generation was grown in the field. This observation also indicated that these traits are greatly influenced by environmental factors, just like other quantitative traits. Transgressive segregation was observed in the population for DD, SW, KW, SWT, and KWT, while it was not obvious for the other traits. The values of skewness and kurtosis for these traits were less than or 
close to 1.0 at least in one generation, indicating these traits fit a normal distribution (Table 2). Abnormal distribution for some traits in the $\mathrm{F}_{3}$ generation might be due to the fact that only 92 lines were planted because of severe self incompatibility considering some QTLs for these traits were located in the region harboring the $S$ loci in this and previous studies (Burke et al., 2002; Tang et al., 2006). ANOVA of the data collected in the $\mathrm{F}_{3}$ generation indicated that variation due to genotype differences was highly significant for all the traits $(P<0.0001)$.

The correlations among these traits are shown in Table 3. Six traits related to seed (kernel) size and seed (kernel) weight (SL, SW, KL, KW, SWT, and KWT) were highly intercorrelated in both generations $(0.46<\mathrm{r}<0.96)$. STR and DD were positively and significantly correlated with these traits related to seed (kernel) size and weight in some cases. As expected, SLW and SKW were positively correlated with SL and KL, but negatively correlated with SW and KW. KSR was negatively correlated with all the other traits.

Table 3: Coefficients of pairwise correlations of the traits investigated in the $F_{2}$ and $F_{3}$ generations

\begin{tabular}{|c|c|c|c|c|c|c|c|c|c|c|}
\hline & SL & SW & $\mathrm{KL}$ & KW & SLW & KLW & SWT & KWT & KSR & STR \\
\hline \multirow[t]{2}{*}{ SW } & $0.57^{\mathrm{a}}$ & & & & & & & & & \\
\hline & 0.55 & & & & & & & & & \\
\hline \multirow[t]{2}{*}{$\mathrm{KL}$} & 0.86 & 0.66 & & & & & & & & \\
\hline & 0.86 & 0.55 & & & & & & & & \\
\hline \multirow[t]{2}{*}{ KW } & 0.44 & 0.89 & 0.61 & & & & & & & \\
\hline & 0.35 & 0.88 & 0.46 & & & & & & & \\
\hline \multirow[t]{2}{*}{ SLW } & 0.51 & -0.40 & 0.22 & -0.51 & & & & & & \\
\hline & 0.64 & -0.28 & 0.49 & -0.40 & & & & & & \\
\hline \multirow[t]{2}{*}{ KLW } & 0.42 & -0.31 & 0.38 & -0.50 & 0.85 & & & & & \\
\hline & 0.55 & -0.25 & 0.59 & -0.44 & 0.87 & & & & & \\
\hline \multirow[t]{2}{*}{ SWT } & 0.70 & 0.84 & 0.82 & 0.80 & NS & NS & & & & \\
\hline & 0.78 & 0.87 & 0.79 & 0.70 & NS & NS & & & & \\
\hline \multirow[t]{2}{*}{ KWT } & 0.61 & 0.83 & 0.80 & 0.85 & -0.24 & NS & 0.96 & & & \\
\hline & 0.67 & 0.81 & 0.80 & 0.78 & NS & NS & 0.91 & & & \\
\hline \multirow[t]{2}{*}{ KSR } & -0.61 & -0.47 & -0.48 & -0.23 & NS & -0.25 & -0.55 & -0.32 & & \\
\hline & -0.56 & -0.48 & -0.35 & NS & -0.21 & -0.24 & -0.59 & -0.22 & & \\
\hline \multirow[t]{2}{*}{ STR } & NS & NS & 0.26 & NS & NS & NS & 0.26 & NS & -0.41 & \\
\hline & NS & NS & NS & NS & NS & 0.22 & NS & NS & -0.46 & \\
\hline \multirow[t]{2}{*}{ DD } & 0.33 & 0.64 & 0.42 & 0.69 & -0.27 & -0.30 & 0.62 & 0.62 & -0.34 & NS \\
\hline & 0.27 & NS & NS & NS & 0.26 & 0.27 & NS & NS & -0.29 & NS \\
\hline
\end{tabular}

a The coefficients in the first and second lines are from the $\mathrm{F}_{2}$ and $\mathrm{F}_{3}$ generations, respectively. Critical values at the 0.05 and 0.01 probability levels are 0.20 and 0.26 , respectively, NS $=$ not significant.

It was observed that some long seeds were not fully filled in this population. Although the correlation between seed length and kernel length is very high, a linear relationship did not exist when the seed length exceeded $1.8 \mathrm{~cm}$ in the greenhousegrown $\mathrm{F}_{2}$ population and $2.0 \mathrm{~cm}$ in the field-grown $\mathrm{F}_{3}$ population (Figure 2). 
Table 4: QTL for the seed morphological traits revealed using interval mapping in the $\mathrm{F}_{2}$ and $\mathrm{F}_{3}$ generations

\begin{tabular}{|c|c|c|c|c|c|c|c|}
\hline Traits & & QTL & LG & Interval & LOD & $\mathrm{R}^{2} \%^{\mathrm{a}}$ & Direction $^{b}$ \\
\hline \multirow[t]{9}{*}{$\overline{\mathrm{SL}}$} & \multirow[t]{5}{*}{$\mathrm{F}_{2}$} & sl1 & 1 & ORS733-1 - ORS509 & 2.5 & 6.5 & $\mathrm{~L}$ \\
\hline & & $\mathrm{sl} 2$ & 10 & ORS595 - ORS78 & 6.2 & 14.4 & L \\
\hline & & sl3 & 13 & T99R21-300 - T99R21-364 & 5.7 & 14.8 & L \\
\hline & & sl4 & 16 & T114R13-600 - T66R22-240 & 4.0 & 8.2 & L \\
\hline & & $\mathrm{sl} 5$ & 17 & T99R21-815 - ORS811 & 4.4 & 8.3 & L \\
\hline & \multirow[t]{4}{*}{$\mathrm{F}_{3}$} & $\mathrm{sl} 2$ & 10 & ORS595 - ORS78 & 6.1 & 15.9 & L \\
\hline & & sl3 & 13 & T99R21-300 - T99R21-364 & 5.3 & 17.3 & L \\
\hline & & sl4 & 16 & T114R13-600 - T66R22-240 & 5.5 & 16.3 & $\mathrm{~L}$ \\
\hline & & $\mathrm{sl} 5$ & 17 & T99R21-815 - ORS811 & 2.7 & 5.4 & $\mathrm{~L}$ \\
\hline \multirow[t]{8}{*}{ SW } & \multirow[t]{4}{*}{$\mathrm{F}_{2}$} & sw1 & 1 & T99R23-115 - T66R19-755 & 2.7 & 6.8 & $\mathrm{~L}$ \\
\hline & & sw3 & 7 & T100R23-260 - ORS331-7 & 2.5 & 5.6 & $\mathrm{~L}$ \\
\hline & & sw4 & 10 & ORS595 - ORS78 & 5.9 & 10.7 & L \\
\hline & & sw5 & 17 & T66R22-550 - S & 4.3 & 9.6 & L \\
\hline & \multirow[t]{4}{*}{$\mathrm{F}_{3}$} & sw1 & 1 & T99R23-115 - T66R19-755 & 5.0 & 10.1 & L \\
\hline & & sw2 & 6 & T110R17-317 - T108R13-495 & 2.5 & 6.6 & L \\
\hline & & sw4 & 10 & ORS595 - ORS78 & 7.5 & 16.3 & $\mathrm{~L}$ \\
\hline & & sw5 & 17 & T66R22-550 - S & 3.1 & 6.1 & L \\
\hline \multirow[t]{8}{*}{$\overline{\mathrm{KL}}$} & \multirow[t]{3}{*}{$\mathrm{F}_{2}$} & $\mathrm{kl1}$ & 4 & ORS366 - ORS337 & 2.7 & 7.1 & $\mathrm{~L}$ \\
\hline & & $\mathrm{kl} 3$ & 10 & ORS595 - ORS78 & 4.8 & 13.1 & L \\
\hline & & $\mathrm{kl} 4$ & 13 & T99R21-300 - T99R21-364 & 5.4 & 13.5 & L \\
\hline & \multirow[t]{5}{*}{$\mathrm{F}_{3}$} & kl1 & 4 & ORS366 - ORS337 & 3.0 & 6.6 & L \\
\hline & & $\mathrm{kl} 2$ & 6 & T100R23-205 - T64R21-365 & 3.1 & 7.5 & L \\
\hline & & $\mathrm{kl} 3$ & 10 & ORS595 - ORS78 & 4.5 & 11.2 & L \\
\hline & & $\mathrm{kl} 4$ & 13 & T99R21-300 - T99R21-364 & 6.5 & 18.4 & L \\
\hline & & $\mathrm{kl} 5$ & 16 & T114R13-600 - T66R22-240 & 5.0 & 16.7 & L \\
\hline \multirow[t]{5}{*}{ KW } & \multirow[t]{2}{*}{$\mathrm{F}_{2}$} & kw2 & 10 & OR78 - T68R23-205 & 3.7 & 8.1 & $\mathrm{~L}$ \\
\hline & & kw3 & 17 & T108R13-348 - T108R13-625 & 4.0 & 23.2 & L \\
\hline & \multirow[t]{3}{*}{$\mathrm{F}_{3}$} & kw1 & 5 & T123R13-400 - ORS733-5 & 2.6 & 7.5 & L \\
\hline & & kw2 & 10 & OR78 - T68R23-205 & 3.3 & 7.8 & L \\
\hline & & kw3 & 17 & T108R13-348 - T108R13-625 & 2.9 & 7.5 & L \\
\hline \multirow[t]{5}{*}{ SLW } & \multirow[t]{3}{*}{$\mathrm{F}_{2}$} & slw2 & 6 & T99R21-515 - T100R19-180 & 3.7 & 7.1 & $\mathrm{~L}$ \\
\hline & & slw3 & 9 & T117R23-210 - T108R13-160 & 3.3 & 6.5 & L \\
\hline & & slw4 & 16 & T114R13-600 - T66R22-240 & 8.1 & 19.8 & L \\
\hline & \multirow[t]{2}{*}{$\mathrm{F}_{3}$} & slw1 & 3 & ORS202 - T99R23-290 & 3.4 & 6.7 & L \\
\hline & & slw4 & 16 & T114R13-600 - T66R22-240 & 6.9 & 15.9 & L \\
\hline \multirow[t]{7}{*}{$\overline{K L W}$} & \multirow[t]{5}{*}{$\mathrm{F}_{2}$} & klw2 & 6 & T99R21-515 - T100R19-180 & 3.9 & 8.6 & L \\
\hline & & klw3 & 9 & T117R23-210 - T108R13-160 & 3.5 & 8.1 & L \\
\hline & & klw4 & 11 & ORS733-11 - T108R13-680 & 3.7 & 8.2 & L \\
\hline & & klw5 & 13 & T99R21-300 - T99R21-364 & 4.3 & 14.4 & L \\
\hline & & klw6 & 16 & ORS656 - T66R19-170 & 6.4 & 14.7 & L \\
\hline & \multirow[t]{2}{*}{$\mathrm{F}_{3}$} & klw1 & 3 & T99R23-290 - T101R19-215 & 4.0 & 8.7 & L \\
\hline & & klw2 & 6 & T99R21-515 - T100R19-180 & 4.2 & 8.1 & L \\
\hline
\end{tabular}


Table 4: QTL for the seed morphological traits revealed using interval mapping in the $\mathrm{F}_{2}$ and $\mathrm{F}_{3}$ generations

\begin{tabular}{|c|c|c|c|c|c|c|c|}
\hline & & klw4 & 11 & ORS733-11 - T108R13-680 & 4.6 & 10.9 & $\mathrm{~L}$ \\
\hline & & klw6 & 16 & ORS656 - T66R19-170 & 7.5 & 14.2 & $\mathrm{~L}$ \\
\hline \multirow[t]{7}{*}{ SWT } & \multirow[t]{4}{*}{$\mathrm{F}_{2}$} & swt1 & 1 & ORS733-1 - ORS509 & 2.9 & 7.2 & $\bar{L}$ \\
\hline & & swt2 & 10 & ORS595 - ORS78 & 6.0 & 17.7 & L \\
\hline & & swt3 & 13 & T99R21-300 - T99R21-364 & 3.0 & 16.2 & L \\
\hline & & swt4 & 17 & T66R22-550 - S & 6.4 & 15.4 & $\mathrm{~L}$ \\
\hline & \multirow[t]{3}{*}{$\mathrm{F}_{3}$} & swt1 & 1 & ORS733-1 - ORS509 & 2.9 & 6.3 & $\mathrm{~L}$ \\
\hline & & swt2 & 10 & ORS595 - ORS78 & 12.3 & 23.3 & $\mathrm{~L}$ \\
\hline & & swt3 & 13 & T99R21-300 - T99R21-364 & 4.2 & 12.6 & $\mathrm{~L}$ \\
\hline \multirow[t]{6}{*}{ KWT } & \multirow[t]{3}{*}{$\mathrm{F}_{2}$} & kwt2 & 10 & ORS595 - ORS78 & 4.4 & 11.6 & $L$ \\
\hline & & kwt3 & 13 & T99R21-300 - T99R21-364 & 2.9 & 14.3 & $\mathrm{~L}$ \\
\hline & & kwt4 & 17 & T66R22-550 - S & 5.7 & 15.4 & $\mathrm{~L}$ \\
\hline & \multirow[t]{3}{*}{$\mathrm{F}_{3}$} & kwt1 & 4 & ORS366 - ORS337 & 2.8 & 6.5 & $\mathrm{~L}$ \\
\hline & & kwt2 & 10 & ORS595 - ORS78 & 8.6 & 18.3 & L \\
\hline & & kwt3 & 13 & T99R21-300 - T99R21-364 & 4.3 & 14.8 & $\mathrm{~L}$ \\
\hline \multirow[t]{14}{*}{ KSR } & \multirow[t]{7}{*}{$\mathrm{F}_{2}$} & ksr1 & 1 & ORS733-1 - ORS509 & 7.2 & 16.2 & $\overline{\mathrm{H}}$ \\
\hline & & ksr2 & 2 & T104R19-260 - T99R21-186 & 4.0 & 10.2 & $\mathrm{H}$ \\
\hline & & ksr4 & 10 & ORS537 - T100R23-380 & 6.4 & 14.8 & $\mathrm{H}$ \\
\hline & & ksr5 & 13 & T99R21-300 - T99R21-364 & 5.1 & 22.1 & $\mathrm{H}$ \\
\hline & & ksr6 & 14 & ORS398-14 - T111R18-456 & 4.8 & 11.7 & $\mathrm{H}$ \\
\hline & & ksr7 & 16 & ORS656 - T66R19-170 & 4.2 & 8.9 & $\mathrm{H}$ \\
\hline & & ksr8 & 17 & T66R22-550 - S & 3.8 & 8.2 & $\mathrm{H}$ \\
\hline & \multirow[t]{7}{*}{$\mathrm{F}_{3}$} & ksr1 & 1 & ORS733-1 - ORS509 & 8.2 & 16.4 & $\mathrm{H}$ \\
\hline & & ksr2 & 2 & T104R19-260 - T99R21-186 & 2.9 & 5.9 & $\mathrm{H}$ \\
\hline & & ksr3 & 6 & T68R17-890 - T110R17-317 & 2.6 & 7.8 & $\mathrm{H}$ \\
\hline & & ksr4 & 10 & ORS537 - T100R23-380 & 8.7 & 17.1 & $\mathrm{H}$ \\
\hline & & ksr5 & 13 & T99R21-300 - T99R21-364 & 2.7 & 8.7 & $\mathrm{H}$ \\
\hline & & ksr6 & 14 & ORS398-14 - T111R18-456 & 3.3 & 6.5 & $\mathrm{H}$ \\
\hline & & ksr7 & 16 & ORS656 - T66R19-170 & 2.5 & 5.1 & $\mathrm{H}$ \\
\hline \multirow[t]{8}{*}{ STR } & \multirow[t]{4}{*}{$\mathrm{F}_{2}$} & str1 & 1 & T117R23-290 - T111R13-140 & 3.9 & 8.9 & $\bar{L}$ \\
\hline & & str2 & 2 & T99R21-186 - T108R13-202 & 3.3 & 19.4 & $\mathrm{~L}$ \\
\hline & & str3 & 14 & ORS398-14 - T111R18-456 & 2.5 & 6.8 & $\mathrm{~L}$ \\
\hline & & str4 & 17 & T123R13-1020 - T100R19-700 & 5.2 & 21.8 & $\mathrm{~L}$ \\
\hline & \multirow[t]{4}{*}{$\mathrm{F}_{3}$} & str1 & 1 & T117R23-290 - T111R13-140 & 4.5 & 10.9 & $\mathrm{~L}$ \\
\hline & & str2 & 2 & T99R21-186 - T108R13-202 & 3.0 & 11.7 & L \\
\hline & & str3 & 14 & ORS398-14 - T111R18-456 & 2.7 & 10.7 & $\mathrm{~L}$ \\
\hline & & str4 & 17 & T123R13-1020 - T100R19-700 & 6.6 & 29.3 & L \\
\hline \multirow[t]{4}{*}{$\mathrm{DD}$} & \multirow[t]{2}{*}{$\mathrm{F}_{2}$} & dd2 & 13 & T99R21-300 - T99R21-364 & 2.7 & 7.2 & $\mathrm{~L}$ \\
\hline & & dd3 & 17 & T66R22-550 - S & 6.8 & 16.8 & L \\
\hline & \multirow[t]{2}{*}{$\mathrm{F}_{3}$} & dd1 & 9 & T110R17-474 - T66R19-750 & 3.6 & 16.4 & $\mathrm{H}$ \\
\hline & & dd3 & 17 & T66R22-550 - S & 8.3 & 24.7 & $\mathrm{~L}$ \\
\hline
\end{tabular}

${ }^{a}$ Amount of phenotypic variation (\%) explained by the QTL

${ }^{b}$ The allele from LSS $(L)$ or HA89 $(H)$ of the locus had a positive effect on this trait 

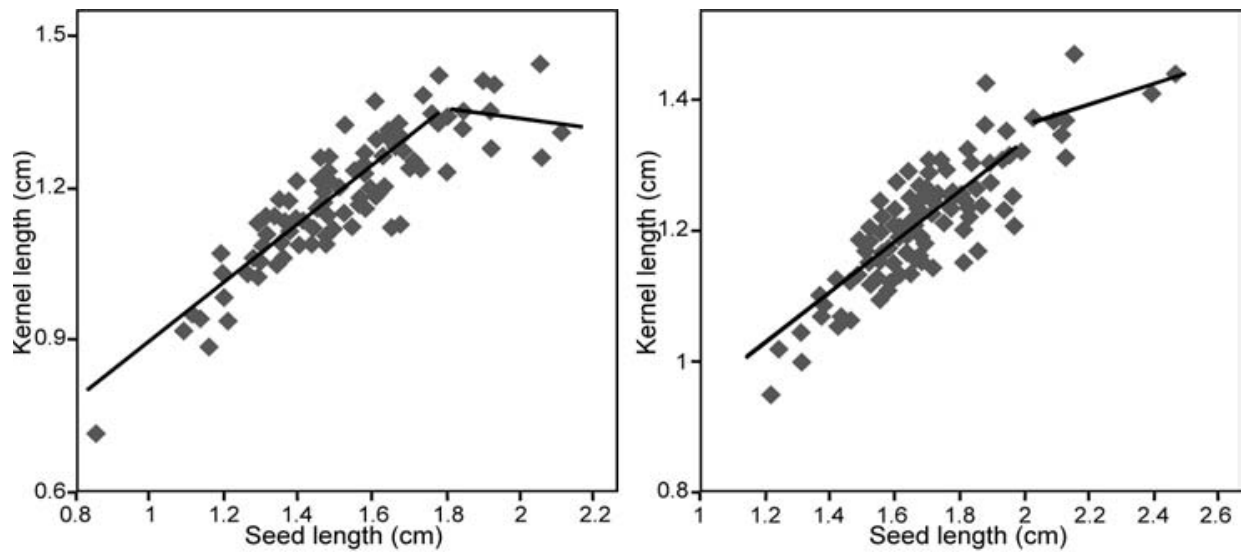

Figure 2: Scatter plots of seed length against kernel length in the $F_{2}$ (left) and $F_{3}$ (right) generations.

\section{Molecular Genetic Linkage Map Construction}

A total of 191 polymorphic fragments were generated from the 40 pairs of TRAP primer combinations (one fixed primer + one arbitrary primer labeled by IR700 or IR800). Only three of them were codominant markers. Each primer combination generated 1 to 12 TRAP markers with an average of 4.8 markers per combination. Among these TRAP markers, 179 were mapped to the 17 linkage groups and 12 were found unlinked. Of the 150 SSRs screened, only 36 (24.0\%) were polymorphic between the two parents, which generated 44 SSR markers.

After a preliminary mapping test, 165 TRAP markers that were evenly distributed across the sunflower genome and the 44 SSR markers were selected to construct the linkage map for QTL analysis. The linkage map had a total length of $1784.3 \mathrm{cM}$, and the average distance between adjacent markers was $8.5 \mathrm{cM}$ (Figure 3). Integration of the 44 previously mapped SSR markers to the TRAP map allowed us to align 15 of the 17 linkage groups to the previously published SSR map except for linkage groups 8 and 12 (Yu et al., 2003). Each linkage group contained 1 to 6 SSR markers.

\section{Mapping the Self-incompatibility (S) Locus}

We observed self-incompatibility on the male parent when it was first grown in the greenhouse in Fargo in winter 2003. All five plants were healthy and developed normally to maturity. However, they had extremely low seed production with only a few seeds per head. Since the plants produced normal pollen, the low seed set could be attributed to self-incompatibility. This self-incompatibility was observed again in the Fargo field plot in summer 2004 when fewer than 20 seeds were obtained from each bagged head. Since seed set on the $F_{1}$ hybrids was normal, we 
inferred that the male parent carries a pair of recessive alleles at the self-incompatibility (S) locus. Of the $120 \mathrm{~F}_{2}$ plants, 28 plants expressed self-incompatibility and had very low seed set. This segregation fit the single gene ratio $\left(c^{2}{ }_{(3: 1)}=0.17\right.$, $\mathrm{p}>0.9$ ). Genetic mapping by molecular markers placed this self-incompatibility (S) locus on LG17 (Figure 3), anchored by SSR markers ORS 598-17 and ORS 811. This $S$ locus has the same proximity in map position as previously reported (Gandhi et al., 2005).

\section{QTL Analysis}

A total of 51 QTLs for these traits were resolved in the two generations including $32(62.7 \%)$ detected in both generations, and individual QTLs explained $5.1 \%$ $29.3 \%$ of phenotypic variation (Table 4). Alleles from LSS at all the QTLs for these traits, except for KSR and DD, had positive effects, and it was opposite for KSR. This was consistent with the performance of this parent for these traits.

For seed or kernel size related traits, (SL, SW, KL, and KW), a total of 18 QTLS were detected in at least one generation, and 12 of them were common in both generations. Eight QTLs were detected for SWT and KWT, with five of them identified in both generations. Furthermore, there were two QTLs for SWT, swt2, and swt3, that shared the same chromosomal locations with two QTLs for KWT, kwt2, and $k w t 3$, respectively, and they explained $11.6 \%-23.3 \%$ of phenotypic variation. The trait of KSR was governed by eight QTLs in this study, six of them were detected in both generations, and individual QTLs explained $5.1 \%-22 \%$ of phenotypic variation.

A total of ten QTLs for SLW and KLW were detected in the two generations, and only four were detected in both generations. Each of them explained $8.1 \%-14.7 \%$ of phenotypic variation. Three QTLs were identified for DD in the $\mathrm{F}_{2}$ or $\mathrm{F}_{3}$ generation, and one of them, $d d 3$, was detected in both generations, which alone explained $16.8 \%$ of phenotypic variation in the $\mathrm{F}_{2}$ generation and $24.7 \%$ in the $\mathrm{F}_{2: 3}$ generation. Alleles at these loci from both parents had positive effects on disk diameter.

\section{Congruence of $\mathbf{Q T L}$}

The 51 QTLs identified in this study were distributed across 14 linkage groups, and there were 12 chromosomal regions that harbored more than two QTLs (Figure 3 ). It is interesting to note that there were six chromosomal intervals containing more than three QTLs contributing to seed or kernel sizes and weight. Two of them, T99R21-300 - T99R21-364 on LG13 and S -T108R13-625 on LG17 clustered 7 and 6 QTLs, respectively. Moreover, two QTLs for disk diameter, dd2 and dd3, were also located in the two regions. There were three regions clustering QTLs for SLW and KLW, two regions with overlapping QTLs for STR and KSR, one region harboring QTLs for KSR and KLW, and one region harboring QTLs for KSR and SW. These results were also consistent with the correlations among these traits (Table 3). However, some clustering QTL for highly correlated seed traits might be controlled by the same gene, such as the QTL for seed (kernel) size and seed (kernel) weight, or the QTL for seed length (width) and kernel length (width). 

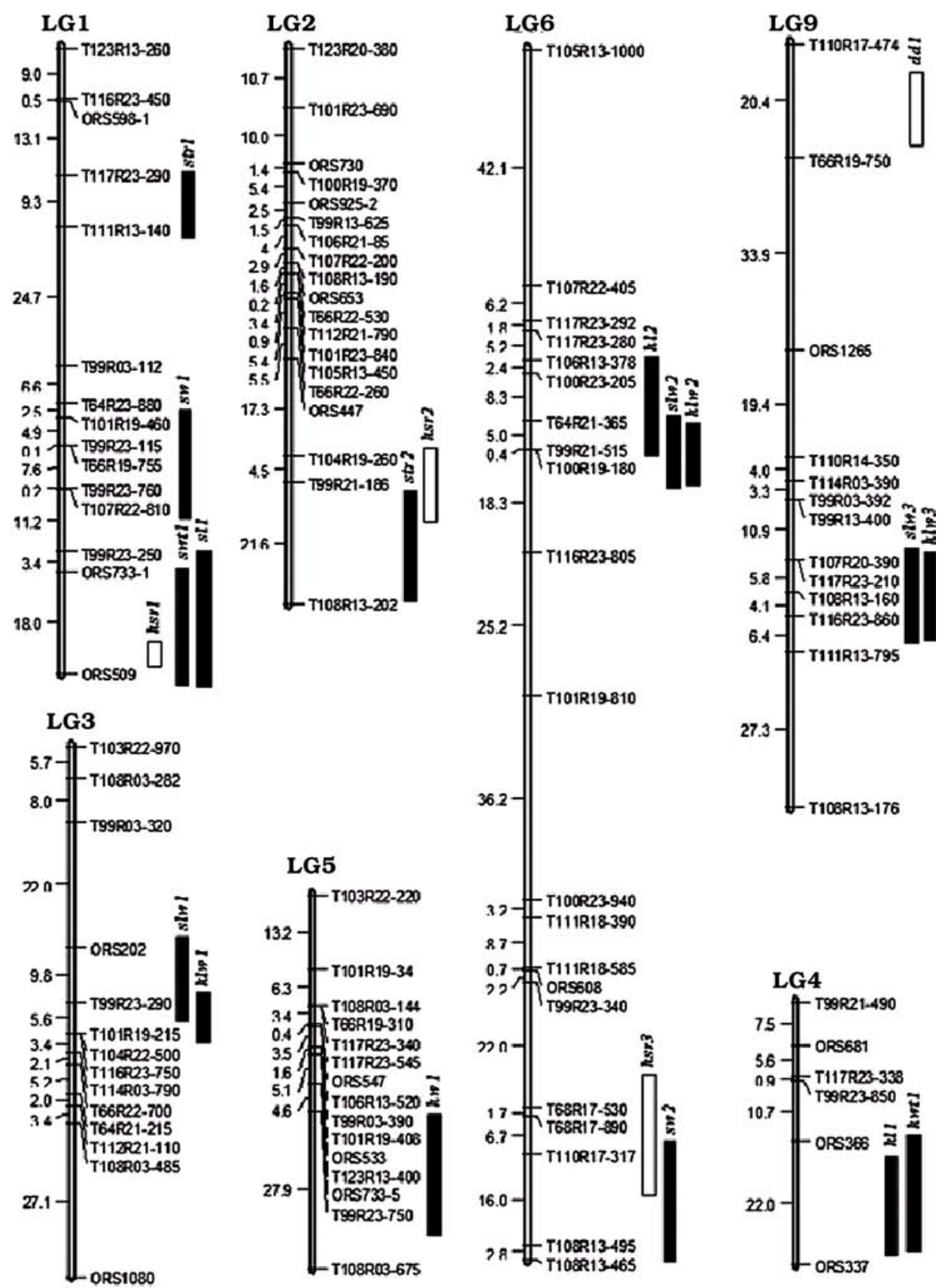

Figure 3a: The genetic linkage map and locations of the $Q T L$ detected in both generations. Designations of markers are on the right and genetic distances (cM) are on the left. 


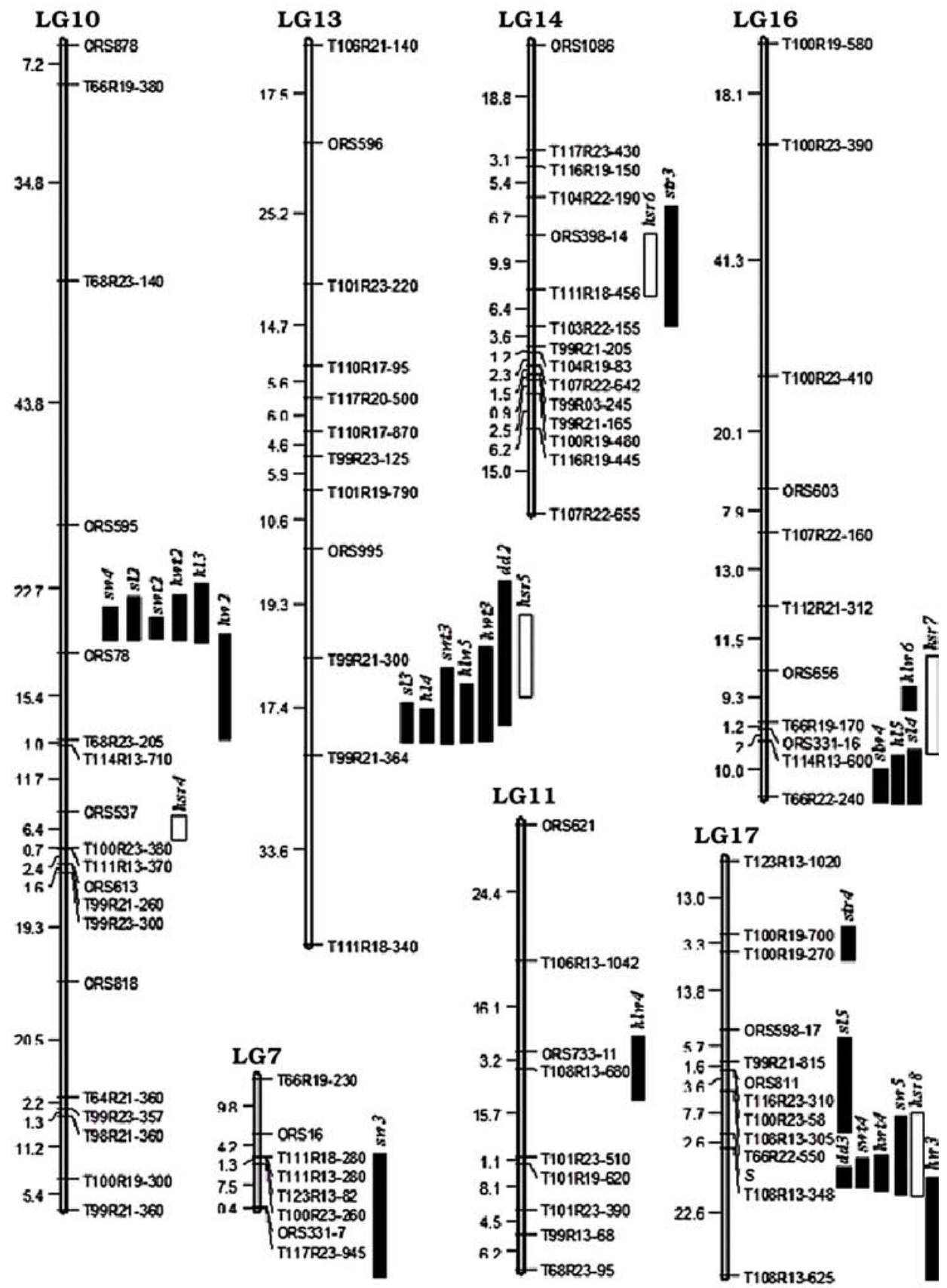

Figure 3b: The genetic linkage map and locations of the QTL detected in both generations. Designations of markers are on the right and genetic distances (cM) are on the left. 


\section{DISCUSSION}

TRAP markers, in combination with SSR markers, have been used to construct linkage maps in wheat, sunflower, and common bean (Liu et al., 2005; Miklas et al., 2006; Hu, 2006; Chen et al., 2007). Here we report the construction of a sunflower TRAP map and the application of the map to QTL analysis. This map contains 165 TRAP markers distributed across 17 linkage groups. Anchored by 44 SSR markers, 15 of the linkage groups were aligned to those of the published SSR maps (Yu et al., 2003). Moreover, a total of 51 QTLs for 11 traits were identified and positioned on this map. TRAP is an efficient PCR-based marker technique for molecular mapping because it can be used to survey multiple loci for polymorphism in a single PCR reaction. For instance, each TRAP PCR reaction generated on average 9.6 polymorphic markers in the mapping population of this study, whereas only $24.0 \%$ of the SSR markers were polymorphic between the two parents and each PCR only detected 1.2 polymorphic markers. Thus, TRAP seems to be more efficient for genome mapping. Similar observations were reported in previous studies (Hu and Vick, 2003; Liu et al., 2005).

The genetic basis of seed morphological traits is complex and controlled by a number of QTLs in rice and wheat (Tan et al., 2000; Groos et al., 2003). In sunflower, Burke et al. (2002) identified 14 QTLs for achene weight, achene width and achene length, each of them explaining 5.4\%-17.8\% of phenotypic variation. Tang et al. (2006) identified 34 QTLs for seed weight, seed length, seed width, seed depth, kernel weight, pericarp weight and kernel-to-pericarp weight ratio. Wills and Burke (2007) detected four QTLs for achene weight, each QTL explaining less than $19.0 \%$ of phenotypic variation. Baack et al. (2008) identified recently six QTLs for achene length and achene mass. In the present study, a total of 48 QTLs for 10 seed morphological traits were detected, and individual QTLs explained 5.1\%-29.3\% of phenotypic variation. These results indicated that seed traits were controlled by multiple genes in sunflower. Although the QTLs for seed traits were distributed across 14 linkage groups, the majority of QTLs were clustered within six chromosomal intervals (Figure 3). These regions could collectively contribute to the typical characteristics of confection type sunflower, which possesses large seed size, seed width, and lower seed to kernel ratio. Through nearby SSR markers, five of the total 19 chromosomal regions containing QTLs for seed traits in this study were previously reported to harbor QTLs underlying similar seed morphological traits. Near the branching gene on LG10 Tang et al. (2006) detected major QTLs for seed length, seed width, seed weight, kernel weight and kernel-to-pericarp weight ratio, which explained more than $40 \%$ of phenotypic variation. Burke et al. (2002) identified two QTLs for achene length and achene width. Wills and Burke (2007) and Baack et al. (2008) also detected a QTL for seed weight. Near the SSR marker ORS656 on LG16, Tang et al. (2006) detected five QTLs for seed traits, and near the locus S on LG17 both Tang et al. (2006) and Burke et al. (2002) identified 
QTLs related to seed traits. In the region of ORS366 - ORS337 on LG4, Tang et al. (2006) identified three QTLs for kernel-to-pericarp weight ratio, 10-pericarp weight, and seed oil concentration. In addition, the QTL for SWT LG1 in this study shares a similar position with the achene weight QTL identified by Wills and Burke (2007). These chromosomal regions that were confirmed to harbor QTLs in different studies are very useful in breeding for confection sunflower lines.

Disk diameter is an agronomically important trait in sunflower, because it is associated with seed number per head. Burke et al. (2002) identified three QTLs for disk diameter in sunflower, and individual QTLs explained 4.6\%-6.0\% of phenotypic variation. Wills and Burke (2007) found disk diameter was controlled by eight QTLs, each QTL explaining less than $13.0 \%$ of phenotypic variation. Baack et al. (2008) recently identified four QTLs for this trait. In the present study, three QTLs were detected in two generations and individual QTLs explained $7.2 \%-24.7 \%$ of phenotypic variation. This indicated that disk diameter was also controlled by multiple genes in sunflower. The QTL near SSR marker ORS995 on LG13 in this study had a similar position to the QTL detected by Burke et al. (2002). Moreover, both Wills and Burke (2007) and Baack et al. (2008) identified a QTL for disk diameter on LG9, which might share a similar position with $d d 1$ which was detected in this study. However, this needs to be further confirmed since only one SSR marker was assigned on LG9 in the current linkage map. It is also interesting to note that two QTLs for disk diameter were located in two regions harboring more than five QTLs for seed traits on LG13 and LG17, and all of the favored alleles were from the confectionery line. Thus, it is possible to increase seed (kernel) size, weight, and disk diameter simultaneously by introgressing the two regions.

According to the analysis of correlation and QTL congruence, the 10 seed traits can be divided into three groups based on size (length, width, and weight), seed shape (ratio of length to width), and stripe. Among the 14 QTLs for seed shape related traits (SLW, KLW) and stripe, only three of them overlapped with the QTLs for seed (kernel) size, suggesting that they had a different genetic basis from the other confection traits. In general, seed size and seed weight are small in the branching head; however, it is unclear whether it is caused by pleiotropic or linkage effects. QTLs for seed size (weight) were detected near the branching $(b)$ locus on LG10, and explained more than $40 \%$ of phenotypic variation (Tang et al., 2006). With a population derived from a cross between branching and nonbranching parents, no QTL for branching was detected on LG10, but QTLs for achene length and weight were still detected in the region harboring $b$. Each QTL explained less than $12.4 \%$ of phenotypic variation (Burke et al., 2002). In the present study, QTLs for seed traits were also detected in the same region on LG10 in the population without segregation for branching, and each QTL explained 7.8\%-23.3\% of phenotypic variation. These results suggested that the QTLs identified near the $b$ locus could be caused by both the pleiotropic effects of $b$ and the linkage disequilibrum between $b$ and the QTL. Although four QTLs for stripe were detected in both generations in 
this study, none of them co-located to the loci controlling hull color, $P$ (in phytomelamin layer) and Hyp (in hypodermal layer), both of which were mapped in a previous report (Tang et al., 2006). Thus, the difference in striping in this study might be mainly produced in the epidermal layer of the hull.

The genetic basis of kernel length is more complex than seed length because seed filling depends not only on the source (photosynthetic assimilates) and sink (seed size), but also on the source-sink relationship (Alkio and Grimm, 2003). Thus, in confection sunflower breeding, seed length should be less than two centimeters.

\section{ACKNOWLEDGEMENTS}

The authors greatly appreciate the technical assistance from Ping Wang and Angelia Hogness. This work was partially supported by USDA-ARS CRIS project 5442-21000-027-OOD and a grant from the National Sunflower Association (Project number 07-P07).

\section{ABBREVIATIONS}

\begin{tabular}{llll}
\hline DD & disk diameter & KL & kernel length \\
KLW & kernel length to width ratio & KSR & kernel-to-seed weight ratio \\
KW & kernel width & KWT & 100-kernel weight \\
QTLs & quantitative trait loci & SL & seed length \\
SLW & seed length to width & SSR & simple sequence repeat \\
STR & stripe & SW & seed width \\
SWT & 100-seed weight & TRAP & target region amplification polymorphism \\
\hline
\end{tabular}

\section{REFERENCES}

Alkio, M. and Grimm, E., 2003. Vascular connections between the receptacle and empty achenes in sunflower (Helianthus annuus L.). J. Exp. Bot. 54: 345-348.

Baack, E.J., Sapir, Y., Chapman, M.A., and Burke, J.M., 2008. Selection on domestication traits and quantitative trait loci in crop-wild sunflower hybrids. Mol. Eco. 17: 666-677.

Berry, S.T., Leon, A.J., Hanfrey, C.C., Challis, P., Burkholz, A., Barnes, S.R., Rufener, G.K., Lee, M. and Caligari, D.S., 1995. Molecular marker analysis of Helianthus annuus L. 2. Construction of an RFLP linkage map for cultivated sunflower. Theor. Appl. Genet. 91: 195-199.

Bert, P.F., Dechamp-Guillaume, G., Serre, F., Jouan, I., Tourvieille de Labrouhe, D., Nicolas, P. and Vear, F., 2004. Comparative genetic analysis of quantitative traits in sunflower (Helianthus annuus L.) 3. Characterisation of QTL involved in resistance to Sclerotinia sclerotiorum and Phoma macdonaldi. Theor. Appl. Genet. 109: 856-874.

Brewer, M.T., Lang, L., Fujimura, K., Dujmovic, N., Gray, S. and Van der Knaap, E., 2006. Development of a controlled vocabulary and software application to analyze fruit shape variation in tomato and other plant species. Plant Physiol. 141: 15-25.

Burke, J.M., Tang, S.X., Knapp, S.J. and Rieseberg, L.H., 2002. Genetic analysis of sunflower domestication. Genetics 161: 1257-1267. 
Chen, J., Hu, J., Vick, B.A. and Jan, C.C., 2006. Molecular mapping of a nuclear male-sterility gene in sunflower (Helianthus annuus L.) using TRAP and SSR markers. Theor. Appl. Genet. 113: 122-127.

Chen, X., Faris, J.D., Hu, J., Stack, R.W., Elias, T.A., Elias, M., Kianian, S.F. and Cai, X., 2007. Saturation and comparative mapping of a major Fusarium head blight resistance QTL in tetraploid wheat. Mol. Breed. 19: 113-124.

Gandhi, S.D., Heesacker, A.F., Freeman, C.A., Argyric, J., Bradford, K. and Knapp, S.J., 2005. The self-incompatibility locus $(S)$ and quantitative trait loci for self-pollination and seed dormancy in sunflower. Theor. Appl. Genet. 111: 619-629.

Gedil, M.A., Wye, C., Berry, S.T., Seger, B., Peleman, J., Jones, R., Leon, A., Slabaugh, A.M. and Knapp, S.J., 2001. An integrated RFLP-AFLP linkage map for cultivated sunflower. Genome 44: 213-221.

Groos, C., Robert, N., Bervas, E. and Charmet, G., 2003. Genetic analysis of grain proteincontent, grain yield and thousand-kernel weight in bread wheat. Theor. Appl. Genet. 106: 1032-1040.

$\mathrm{Hu}$, J. and Vick, B.A., 2003. Target region amplification polymorphism, a novel marker technique for plant genotyping. Plant Mol. Biol. Rep. 21: 289-294.

$\mathrm{Hu}$, J., 2006. Defining the sunflower (Helianthus annuus L.) linkage group ends with the Arabidopsis-type telomere sequence repeat-derived markers. Chromosome Res. 14: 535548.

Lai, Z., Livingstone, K., Zou, Y., Church, S.A., Knapp, S.J., Andrews, J. and Rieseberg, L.H., 2005. Identification and mapping of SNPs from ESTs in sunflower. Theor. Appl. Genet. 111: 1532-1544.

Lander, E.S. and Botstein, D., 1989. Mapping Mendelian factors underlying quantitative traits using RFLP linkage maps. Genetics 121: 185-199.

Lander, E.S., Green, P., Abrahamson, J., Barlow, H., Daly, M., Lincoln, S. and Newbury, L., 1987. MAPMAKER: an interactive computer program for constructing genetic maps of experimental and natural populations. Genomics 1: 174-175.

Leon, A.J., Lee, M., Rufener, G.K., Berry, S.T. and Mowers, R.P., 1996. Genetics mapping of a locus (hyp) affecting seed hypodermis color in sunflower. Crop Sci. 36: 1666-1668.

Lincoln, S.E., Daley, M.J. and Lander, E.S., 1993. Mapping genes controlling quantitative traits with MAPMAKER/QTL 1.1: a tutorial and reference manual, $2^{\text {nd }} e d$. Whitehead Institute Technical Report. Cambridge.

Liu, Z.H., Anderson, J.A., Hu, J., Friesen, T.L., Rasmussen, J.B. and Faris, J.D., 2005. A wheat intervarietal genetic linkage map based on microsatellite and target region amplified polymorphism markers and its utility for detecting quantitative trait loci. Theor. Appl. Genet. 111: 782-794.

Mestries, E., Gentzbittel, L., Tourvieille de Labrouhe, D., Nicolas, P. and Vear, F., 1998 Analyses of quantitative trait loci associated with resistance to Sclerotinia sclerotiorum in sunflowers (Helianthus annuus L.) using molecular markers. Mol. Breed. 4: 215-226.

Micic, Z., Hahn, V., Bauer, E., Schön, C.C., Knapp, S.J., Tang, S. and Melchinger, A.E., 2004. QTL mapping of Sclerotinia midstalk-rot resistance in sunflower. Theor. Appl. Genet. 109: 1474-1484.

Miklas, P.N., Hu, J., Grünwald, N.J. and Larsen, K.M., 2006. Potential application of TRAP (targeted region amplified polymorphism) markers for mapping and tagging disease resistance traits in common bean. Crop Sci. 46: 910-916.

Miller, J.F. and Fick, G.N., 1997. The genetics of sunflower. In: Schneiter AA (ed.) Sunflower Technology and Production. Crop Sci. Soc. Amer. Publishers, Madison, WI, USA. pp. 441-449.

Mokrani, L., Gentzbittel, L., Azanza, F., Fitamant, L., Al-Chaarani, G. and Sarrafi, A., 2002. Mapping and analysis of quantitative trait loci for grain oil content and agronomic traits using AFLP and SSR in sunflower (Helianthus annuus L.). Theor. Appl. Genet. 106: 149156.

Rönicke, S., Hahn, V., Vogler, A. and Friedt, W., 2005. Quantitative trait loci analysis of resistance to Sclerotinia sclerotiorum in sunflower. Phytopathology 95: 834-839.

Rojas-Barros, P., Jan, C.C. and Hu, J., 2005. Mapping of a recessive branching gene in RHA 271 using molecular markers. Proc $27^{\text {th }}$ Sunflower Res. Workshop, January 12-13, Fargo, ND. (Available at: http://www.sunflowernsa.com/research/research-workshop/ documents/rojas_mappinggene_05.pdf, accessed on Dec. 14, 2007) 
Tan, Y.F., Xing, Y.Z., Li, J.X., Yu, S.B., Xu, C.G. and Zhang, Q., 2000. Genetic bases of appearance quality of rice grains in Shanyou 63, an elite rice hybrid. Theor. Appl. Genet. 101: 823-829.

Tang, S.X., Leon, A., Bridges, W.C. and Knapp, S.J., 2006. Quantitative trait loci for genetically correlated seed traits are tightly linked to branching and pericarp pigment loci in sunflower. Crop Sci. 46: 721-734.

Tang, S., Yu, J.K., Slabaugh, M.B., Shintani, D.K. and Knapp, S.J., 2002. Simple sequence repeat map of the sunflower genome. Theor. Appl. Genet. 105: 1124-1136.

Wills, D.M. and Burke, J.M., 2007. Quantitative trait locus analysis of the early domestication of sunflower. Genetics 176: 2589-2599.

Yu, J.K., Tang, S., Slabaugh, M.B., Heesacker, A., Cole, G., Herring, M., Soper, J., Han, F., Chu, W.C., Webb, D.M., Thompson, L., Edwards, K.J., Berry, S., Leon, A.J., Olungu, C., Maes, N. and Knapp, S.J., 2003. Towards a saturated molecular genetic linkage map for cultivated sunflower. Crop Sci. 43: 367-387.

\section{MAPEO DE LOCI PARA CARACTERES CUANTITATIVOS (QTL) GUE CONTROLAN MORFOLOGÍA DE SEMILLAS Y DIÁMETRO DEL DISCO EN GIRASOL (Helianthus annuUs} L.)

\section{RESUMEN}

La morfología de las semillas y el diámetro del disco son los caracteres agronómicos más importantes para el girasol confitero. Este trabajo informa los resultados del análisis de los loci para caracteres cuantitativos (QTLs) que subyacen 10 caracteres morfológicos de las semillas, incluyendo tamaño de aquenio y pepita, forma y estriado y diámetro del disco en una población $\mathrm{F}_{2} \mathrm{y}$ las familias $\mathrm{F}_{2: 3}$ derivadas de un cruzamiento entre un material del tipo oleaginoso y uno confitero. Se construyó un mapa de ligamiento consistente en 165 marcadores de polimorfismo de amplificación de regiones objetivo (TRAP) y 44 marcadores de repetición de secuencias simples (SSR) a partir de 120 plantas $\mathrm{F}_{2}$. Este mapa contiene 17 grupos de ligamiento y explora una distancia genética total de $1784.3 \mathrm{cM}$. Se detectó un total de 51 QTLs, 32 de los cuales de identificaron en ambas generaciones. Cada QTL explicó un 5.1-29.3\% de la variación fenotípica, lo que sugiere que estos atributos están controlados por múltiples genes. La mayoría de los QTLs están agrupados en seis regiones cromosómicas. Dos de los tres QTLs identificados para diámetro del disco están localizados en dos de las seis regiones cromosómicas. Además, alelos de la línea confitera en dichos QTLs presentaron efectos positivos sobre estos atributos. Tanto la congruencia de QTLs como los análisis de correlación revelaron que bases genéticas diferentes son responsables de la expresión de los atributos forma de semilla, estriado y otros caracteres de los confiteros. La información generada por este estudio facilitará el mejoramiento del girasol confitero. 


\title{
ÉTABLISSEMENT D'UNE CARTE DE LOCI DES CARACTÉRISTIQUES QUANTITATIVES (QTL) CONTRÔLANT LA MORPHOLOGIE DE LA GRAINE ET LE DIAMÈTRE DU CAPITULE DU TOURNESOL (Helianthus annuus L.)
}

\author{
RÉSUMÉ
}

La morphologie de la graine et le diamètre du capitule sont les caractères agronomiques les plus importants pour le tournesol de bouche. Cet article rapporte les résultats d'une analyse de LCQ associés à 10 caractères morphologiques parmi lesquels la taille du grain, sa forme et ses stries et le diamètre du capitule, à partir d'une population $\mathrm{F}_{2}$ et de sa descendance $\mathrm{F}_{2}: \mathrm{F}_{3}$ issue d'un croisement entre une lignée de type "huile" et d'une lignée de type "de bouche". Une carte de liaison a été établie à partir de 165 marqueurs TRAP (target region amplification polymorphism) et de 44 marqueurs microsatellites (SSR), et sur 120 individus $\mathrm{F}_{2}$. Cette carte comporte 17 groupes de liaison et couvre une distance génétique totale de $1784.3 \mathrm{cM}$. Au total, 51 LCQ ont été mis en évidence et 32 d'entre eux l'ont été pour les deux générations. Chaque LCQ explique 5.1 à $29.3 \%$ de la variance phénotypique totale, ce qui suggère un contrôle multigénique. La plupart des LCQ se concentre sur six régions chromosomiques. Deux des trois QTL identifiés pour le diamètre du capitule co-localisent avec deux de ces six régions chromosomiques. De plus, le parent de type "de bouche" apporte les allèles favorables à ces caractères. La cohérence des résultats obtenus sur les LCQ et les analyses de corrélations mettent en évidence l'existence de bases génétiques distinctes pour la forme de la graine, ses stries, et les autres caractères d'intérêt pour le tournesol de bouche. L'information produite par cette étude facilitera l'amélioration génétique des tournesols de bouche. 
